\title{
Élite y comercio en el temprano siglo XVII rioplatense
}

\author{
Macarena Perusset Veras \\ Universidad de Buenos Aires, Argentina \\ macarena.perusset@gmail.com
}

\begin{abstract}
Resumen
El presente artículo trata sobre el proceso de construcción y consolidación de la élite rioplatense a principios del siglo XVII. Su objetivo principal es describir, analizar y discutir las estrategias que desplegaron ciertos personajes, que tenían el interés de constituirse en el sector dominante que estuvo al frente de los asuntos políticos, económicos y sociales de la ciudad de Buenos Aires hasta mediados del siglo XVII. Una parte fundamental de este estudio se concentra en el surgimiento del comercio ilícito por el puerto de Buenos Aires.

Palabras clave: BUENOS AIRES, ÉLITES, COMERCIO, SIGLO XVII.
\end{abstract}

\begin{abstract}
This article adresses the construction and consolidation of elites in the Río de la Plata at the beginning of the $17^{\text {th }}$ century. Its main objetive is to describe, analyze, and discuss the strategies deployed by certain actors whose interest it was to constitute themselves as the dominant faction leading political, economic, and social issues in Buenos Aires up until the middle of the $17^{\text {th }}$ century. A crucial part of this investigation centers on the apearance of illegal commerce in Buenos Aires. Key words: BUENOS AIRES, ELITES, TRADE, $17^{\mathrm{TH}}$ CENTURY.
\end{abstract}


La historiografía sobre las élites en Hispanoamérica se ha consagrado considerablemente a la aproximación de las estrategias, trayectorias y actuaciones de sus miembros en diversas instituciones y regiones de los virreinatos españoles en Indias. En este sentido, el análisis genealógico se consolidó como una herramienta válida. Sin embargo, su desarrollo y movilidad a lo largo del siglo XVII no han merecido suficiente atención por parte de los investigadores1. Esta falta de atracción hacia el análisis de las élites del temprano XVII se diferencia del interés prestado a las que dominaron en la Hispanoamérica de fines del siglo XVIII, para estudiar las cuales se ha abordado desde el recambio social dentro de las mismas hasta el impacto de la política borbónica en su autonomía de acción. En este sentido también se destacaron los estudios sobre las estrategias de los sectores dirigentes tradicionales para mantener sus privilegios frente a las distintas presiones sociales, consolidando ciertos elementos distintivos, como las buenas costumbres y un alto rango social ${ }^{2}$.

Es bien conocida la vida de los vecinos y la estructura social de algunas ciudades del virreinato del Perú, la mayor parte de las cuales se componía de una clase dirigente y una clase inferior. La primera era, en casi todos los lugares, principalmente española y criolla, compuesta por altos oficiales de la Corona, poderosos comerciantes, familias pertenecientes a órdenes militares, miembros del Cabildo y los jerarcas de la Iglesia, entre otros. Pero el conocimiento de la construcción y composición de la élite rioplatense temprana y los medios que usaron sus integrantes para dominar la población restante es aún insuficiente. Por lo tanto, nos preguntamos quiénes eran los miembros que componían la élite porteña, cómo estaba formada y cómo se produjo su conformación. Para responder, en este trabajo exploramos, por un lado, la conformación del sector dirigente de la sociedad porteña, e indagamos las principales características de su consolidación, considerando las distintas etapas que formaron parte del proceso de surgimiento de la élite del lugar, por el otro.

\section{Migraciones}

A partir del siglo XVI comenzaron a producirse, en la sociedad española, grandes cambios económicos, políticos y sociales que afectaron de distinta manera todos

\footnotetext{
${ }^{1}$ Entiendo por élite la definición brindada por Clara López Beltrán, quien la considera como el conjunto de hombres y mujeres que concentran en sus manos el manejo del poder, del honor y de la riqueza.

${ }^{2}$ L. Quarleri, "Élite local, burocracia y reformas borbónicas: La administración de temporalidades de La Rioja". Revista Población y Sociedad (Tucumán, Argentina), núms. 8 y 9 (2001-2002): 177-210. J. L. Romero, Latinoamérica: las ciudades y las ideas (Buenos Aires: Siglo XXI. 1986).
} 
los aspectos de la vida. Al producirse un deterioro real en las circunstancias económicas, migrar fuera de la península se convirtió en una alternativa atractiva ${ }^{3}$.

Muchos de los españoles que pasaron a América poseían títulos de nacimiento noble, aunque eran los hombres procedentes de las capas inferiores de la nobleza. Eran jóvenes de entre 20 y 30 años, y sus actitudes y ambiciones inspiraron y animaron el movimiento migratorio, ya que un hidalgo dispuesto a arriesgar todo al cruzar el Atlántico lo hacía, obviamente, con la esperanza de mejorar su situación. La idea del oro les daba a estos hombres la visión de una forma de vida más allá de todo lo que nunca hubieran podido imaginar ${ }^{4}$.

Steve Stern señala que las primeras oleadas de españoles que llegaron a América en tiempos de la conquista traían consigo objetivos o "utopías de conquista". Entre ellos, el ansia de grandes riquezas parece haber contagiado a todos los grupos que se dedicaron a la colonización, ya que estas empresas tenían intereses económicos y mercantiles, pues la meta de los españoles que se dirigieron a América era conseguir beneficios y lucro. De la misma manera, los burócratas y letrados se vieron impulsados por ese mismo fin: los movía inicialmente esa codicia de acumulación de tesoros que animaba toda la época.

Frente a estas oleadas migratorias, la Corona intentaba frenar la llegada de personas "no deseadas" para poblar el Nuevo Mundo. En este sentido, y pese a que hasta 1640 portugueses y flamencos fueron súbditos de España, los mismos no eran considerados españoles en estricto sentido. Una abundante legislación daba cuenta de las trabas que se les imponían a los europeos no hispanos que aspiraran pasar a Indias. La síntesis de estas premisas legales fue la Pragmática de 1552, que, además de prohibirles su paso a América, les impedía comerciar directamente con ella ${ }^{6}$. Por supuesto, tal prohibición no se cumplió terminantemente, ya que, por un lado, muchos pudieron cruzar el Atlántico en condición de ilegales y, por otro, algunos obtuvieron permisos que fueron otorgados por la misma Corona?

\footnotetext{
${ }^{3}$ I. Altman, "A new world in the old: local society and spanish emigration to the Indies", en To make America. European emigration in the early modern period. Comps. Altman y Honr (California: University of California Press, 1991), 30-58.

${ }^{4}$ J. A. Maravall, Estudios de historia del pensamiento español (Madrid: Ediciones Cultura Hispánica, 1973).

5 S. Stern, "Paradigmas de la conquista: historiografía y política". Boletín del Instituto de Historia Argentina y Americana Dr. E. Ravignani, 3a serie (Buenos Aires), núm. 6 (1992): 94-109.

${ }^{6}$ F. Armas Asin, Liberales, protestantes y masones. Modernidad y tolerancia religiosa en el Perú del siglo XIX (Lima: Pontificia Universidad Católica del Perú y Centro de Estudios Regionales Andinos "Bartólome de Las Casas", 1998).

${ }^{7}$ Un caso que ejemplifica estas excepciones es el de Diego de Vega, potentado portugués de la región, que arribó a Buenos Aires en 1590 y obtuvo un permiso real para movilizar e
} 
Por otra parte, la utopía de preeminencia social significaba escapar de la asfixiante subordinación y de las dificultades por las que estaba atravesando la sociedad española, y además elevarse a una posición de mando y autoridad sobre personas dependientes en una nueva sociedad, adquirir derechos para aspirar a altos honores y servicios que legitimaban la recompensa y adquirir superioridad social. En el siglo XVII había pasado la época en la que los conquistadores presumían e idealizaban una carrera que incluía dos etapas, siendo la primera la adquisición de riquezas en América y la segunda, el ansiado retiro a la península. Ahora la meta principal no se limitaba a regresar a la España natal, luego de haber extraído cuanta riqueza fuese posible; se trataba, en la mayoría de los casos, de quedarse y asentarse en las nuevas tierras para aprovechar al máximo todos los beneficios posibles de obtener.

Por lo tanto, igual que en las primeras fases de la conquista, en la época que nos ocupa, el temprano siglo XVII, la ampliación de oportunidades de riqueza, con la expectativa de mejorar la situación económica y social, constituyó la motivación más importante que empujó a los peninsulares a migrar a Indias. Todo esto llevó a que ese sentimiento de lucro invadiera las sociedades coloniales del siglo XVII.

Sin embargo, en una zona marginal y pobre como el Río de la Plata, la búsqueda de tesoros se desvaneció rápidamente. Los colonizadores que se establecieron allí tuvieron que buscar otras vías de enriquecimiento y de preeminencia social. En relación con esto último, a diferencia de lo que sucedía en la España de los Austrias, donde las actividades comerciales eran consideradas inferiores, en algunas regiones de Indias, frente a la imposibilidad de reproducir una "vida aristocrática" con los medios utilizados por la vieja nobleza ibérica, el comercio cobró una dimensión significativa como vía de acceso a la riqueza.

\section{Primeros pobladores}

El número de personas que formaron parte del grupo con el que Juan de Garay realizó la fundación de Buenos Aires en 1580 no excedía de 76 individuos. Catorce de estos fundadores, incluido Garay, eran españoles peninsulares. El número restante correspondería a españoles criollos y mestizos nacidos en Asunción ${ }^{8}$. Estos primeros habitantes de Buenos Aires se desempeñaron dentro de los límites de una economía incipiente. La comercialización hacia el exterior de la ciudad era

instalar allí a su familia. R. Molina, Don Diego Rodríguez Valdez y de la Banda, el tercer gobernador del Paraguay y Río de la Plata por S. M. después de la repoblación de Buenos Aires. 1599-1600 (Buenos Aires: Secretaría de Cultura, 1949).

${ }^{8}$ J. Torre Revello, La sociedad colonial. Buenos Aires entre los siglos XVI y XIX (Buenos Aires: Ediciones Pannediele, 1970). 
restringida, debido a los pocos sobrantes para el intercambio 9 . A pesar de las limitaciones y debido al vínculo poblacional que unía dichas regiones (Buenos Aires-Asunción) pudieron desarrollar, aunque rudimentario, una suerte de intercambio. Se desarrolló el comercio no solo con Paraguay, sino con la costa del Brasil, poco después de la fundación de Buenos Aires ${ }^{10}$. En consecuencia, la actividad económica de los habitantes locales se desplegó en dos esferas: la tenencia de la tierra y el comercio.

Estos primeros pobladores (los conquistadores y sus descendientes) fueron también los primeros vecinos de la ciudad. Dentro del conjunto que reunía a los españoles nacidos en la península o en las colonias, y más tarde también a los mestizos, los vecinos constituían un grupo selecto que poseían unos derechos y tenían unos deberes que les eran propios ${ }^{11}$. A consecuencia de ese mismo carácter, recibieron de la Corona mercedes de tierra y encomiendas de indios. Desde el comienzo de la colonización, los derechos a la vecindad estuvieron circunscritos a los poseedores de encomiendas. Sin embargo, en el Río de la Plata estas eran comparativamente más pequeñas que en el Perú $\mathrm{y}$, en consecuencia, los réditos también eran considerablemente menores. Por lo tanto, el derecho a la vecindad provenía no solo de la condición de encomendero, sino también, y mayormente, de la calidad de propietario de extensiones de tierra.

En un primer momento, por sus propias características, la jerarquía interna de la comunidad de vecinos se organizaba con criterios de fuerte contenido nobiliario: los méritos y las distinciones personales de un individuo o de sus antecesores, en los cuales reposaba su pretensión de reconocimiento de determinados derechos. Tales méritos y distinciones nacían de las proezas en la conquista, los servicios al monarca, las cualidades nobiliarias heredadas o todo al mismo tiempo ${ }^{12}$. Dichas pretensiones se fundamentaban en el pacto contractual, de corte medieval, establecido entre el monarca y sus vasallos. Como sabemos, la sociedad perteneciente a la Edad Media tenía un carácter patrimonial y estaba construida con una concepción de obligaciones mutuas, simbolizadas en las palabras servicio y

9 J. Gelman, "Cabildo y élite local: Buenos Aires en el siglo XVII". Revista Latinoamericana de Historia Económica y Social (Lima), 6 (1985):3-27.

${ }^{10}$ R. Levillier, Correspondencia de la Ciudad de Buenos Aires con los Reyes de España. 2 vol. (Buenos Aires: Municipalidad de Buenos Aires, 1915).

11 Ser vecino en el siglo XVII incluía a los habitantes, generalmente de origen o ascendencia española, con casa poblada en la ciudad y residencia continua de por lo menos cuatro años. Debían también ser miembros activos en la comunidad y estar dispuestos a su defensa cuando fuese neceario. Uno de los principales atractivos que ofrecía la vecindad era el privilegio de poder ser elegido para formar parte del Cabildo.

${ }^{12}$ Z. Moutoukias, Contrabando y control colonial en el siglo XVII (Buenos Aires: Centro Editor de América Latina, 1988). 
merced. Fue este tipo de sociedad la que se reconstruyó durante el reinado de los Reyes Católicos y se implantó, con algunas reformas, en América ${ }^{13}$.

Dentro de este marco, la monarquía era el centro de la organización de la sociedad española. En una sociedad armónica, el rey, como delegado de Dios en la tierra, ejercía una vigilancia constante dentro de la estructura de la ley. Esto significaba que debía asegurar que cada vasallo recibiera sus derechos y cumpliera las obligaciones que le correspondían en virtud de su posición social. En esta teoría se encuentra implícita la relación contractual entre el rey y sus súbditos, en la cual la monarquía se volvía una tiranía si este descuidaba el bien común. La diferencia entre el buen rey y el tirano era que el primero procuraba que lo justo fuese recompensado, es decir, premiar o retribuir los servicios prestados otorgando a sus vasallos mercedes, cargos y honores de acuerdo con cada servicio.

En virtud de este acuerdo, a los dos años de fundada la ciudad de la Trinidad del Puerto de Santa María de Buenos Aires, Juan de Garay -en nombre del monarcarepartió entre los encomenderos del puerto un cierto número de indios ${ }^{14}$. Estos vecinos eran los que gozaban del usufructo de las pobres encomiendas otorgadas. La encomienda suponía para los españoles de la generación de los colonizadores una forma de compensación ante los trabajos, los peligros y los gastos realizados para someter los territorios descubiertos para la Corona. De esta manera, entonces, además de contar con las encomiendas de indios, los vecinos de Buenos Aires poseían parcelas de tierra en la ciudad y en las afueras, que también habían adquirido como merced real. Pero esto no era suficiente para aquellos que aspiraban a un estatus señorial y que traían de sus regiones de origen la idea del riguroso carácter degradante del trabajo manual, pues para ellos la tierra tenía poco valor sin una mano de obra forzada que la trabajara.

A pesar de las mercedes recibidas, la mayoría de los fundadores de Buenos Aires no se avecindaron en el lugar. Y pese a que en 1583 arribaron de España cincuenta personas para reforzar la población, una información suministrada en 1595 por Rodrigo Ortiz de Zárate daba cuenta que la naciente ciudad contaba con apenas cincuenta vecinos. A 15 años de su fundación, Buenos Aires poseía todavía un vecindario reducido. Como consecuencia del rápido abandono que hicieron de la ciudad algunos de sus fundadores, los indios a ellos encomendados quedaron en libertad o se fugaron ${ }^{15}$. La carencia de indios sometidos a la encomienda desde el primer reparto hecho por Garay hizo que el vecindario, a través del Cabildo -y en

${ }^{13}$ J. H. Elliot, "Europa y América en los siglos XVI y XVII", en Historia de América Latina, comp. Leslie Bethell. t. 2, América Latina colonial: Europa y América en los siglos XVI, XVII y XVIII (Barcelona: Crítica, 1990).

${ }^{14}$ Torre, La sociedad colonial.

${ }^{15}$ Ibídem. 
1590 por medio del apoderado de la ciudad, Beltrán Hurtado-, gestionara en la Corte la introducción de negros destinados al trabajo y demás quehaceres:

...que atento a la necesidad y pobreza de la tierra y falta de servicio que tenemos nos conceda y haga merced de algunas licencias de esclavos de Guinea y siendo S. M. servida que sean hasta en cantidad de quinientos o los que S. M mandare ${ }^{16}$.

Pese a que la vía de ingreso oficial de mercaderías procedente de Europa era Portobelo, el rey autorizó el ingreso de esclavos por el puerto de Buenos Aires, ya que la ruta del Río de la Plata contaba con reales ventajas sobre la primera ${ }^{17}$. Gracias a estas ventajas, una Real Cédula del 30 de enero de 1595 permitía al portugués Pedro Gómez Reynell, concesionario de los esclavos en el Nuevo Mundo, introducir negros por el Río de la Plata, licencia que duraría hasta 1605 , no obstante haberse decretado el cierre del puerto en $1594^{18}$.

\section{Nuevos habitantes: los Confederados}

Desde las noticias de las primeras experiencias comerciales practicadas por el obispo del Tucumán ${ }^{19}$, y a partir de 1602 , momento en que se otorgaron los

\footnotetext{
${ }^{16}$ Correspondencia de la ciudad de Buenos Aires con los Reyes de España. 20-02-1590. Levillier, Correspondencia de la Ciudad.

${ }^{17}$ Un informe brindado por el gobernador Diego Rodríguez Valdez y de la Banda daba cuenta de los riesgos y obstáculos que debía sufrir la plata en su viaje de Potosí a Arica, Paita, Panamá, Portobelo, Cartagena, La Habana hasta llegar a la península. Comparaba desfavorablemente la amenaza de enemigos, enfermedades, demoras y pasajes peligrosos que debían sortearse con "las 400 leguas que mediaban entre Potosí y Buenos Aires, de las que 300 eran de camino llano y la navegación cómoda de 40 ó 45 días que separaban a Buenos Aires de Sevilla". R. Molina, "Una historia desconocida sobre los navíos de registro arribados a Buenos Aires en el siglo XVII", Revista Historia (Buenos Aires), 23 (1959):5-67.

${ }^{18}$ La institución de la esclavitud negra ya se conocía en la sociedad medieval mediterránea. Los comerciantes portugueses habían importado esclavos negros para Portugal desde mediados del siglo XIII, y su número en la Península Ibérica aumentó considerablemente en el siglo XV, cuando la penetración portuguesa al sur de la costa de Guinea creó nuevas fuentes de suministro. Al gozar de un monopolio de comercio eficaz, los comerciantes portugueses abastecieron ampliamente el mercado español desde la década de 1460 . Mientras que Lisboa era la ciudad con mayor población negra en la península, pronto hubo un número sustancial de esclavos en muchas de las principales ciudades españolas, donde se empleaban para el servicio doméstico. La trata de esclavos, tan conocida y practicada por los portugueses, sería crucial para la conformación de la élite rioplatense, compuesta en gran número por los comerciantes lusitanos que llegaron al puerto en momentos posteriores al establecimiento de los primeros pobladores. Ibídem.

19 El obispo Francisco de Victoria se vió involucrado en las primeras experiencias comerciales en 1585 y 1587. Z. Moutoukías, "Redes, autoridad y negocios: racionalidad
} 
permisos para comerciar a los vecinos de Buenos Aires, mercaderes y marinos españoles y portugueses provenientes de la península o de otras regiones de la América colonial comenzaron a entrar y a establecerse en el Río de la Plata ${ }^{20}$. Debido a la rudimentaria práctica mercantil del grupo conformado por los primeros conquistadores-hacendados-encomenderos, Buenos Aires se abría ella misma a la coyuntura de los comerciantes recién llegados. Atraídos principalmente por el comercio que se desarrollaba en la región, a los portugueses los alentaba también el hecho de no encontrarse en el Río de la Plata ningún Tribunal de la Inquisición, ya que una gran cantidad de los que vinieron a América eran probablemente de origen judío ${ }^{21}$.

A partir de 1590, comenzaron a arribar comerciantes portugueses a Buenos Aires: así lo hicieron Diego de Vega ${ }^{22}$, Antonio Fernández Barrios ${ }^{23}$ y Antonio de Sosa ${ }^{24}$,

empresaria y consenso colonial en Buenos Aires (segunda mitad del siglo XVIII)", Annales (Buenos Aires), 47 núm. 4-5 (julio-octubre 1992):3-23.

${ }^{20}$ J. Gelman, "Economía natural-Economía monetaria. Los grupos dirigentes de Buenos Aires a principios del siglo XVII". Anuario de Estudios Americanos (Sevilla), XLIV (1987): 89-107

${ }^{21}$ Luego de haber sido expulsados de Nápoles en 1541y de España y de Sicilia en 1492, los exiliados judíos se dirigieron en dos direcciones: el islam mediterráneo y los países del Atlántico. Portugal, que los había tolerado en su seno después de 1492, constituyó el punto de partida de otra gran multitud. Amsterdam, Hamburgo, Londres, entre otros, fueron puntos privilegiados de llegada de mercaderes ya ricos, y que continuarían enriqueciéndose rápidamente. F. Braudel, Civilización material, economía y capitalismo. Siglos XV-XVIII. (Madrid: Alianza Editorial, 1984). De la misma manera, los portugueses judíos invadieron la América española, a pesar de no estar autorizados a ello. Encontramos comerciantes principales y otros de rango menor que abrieron tiendas y pulperías donde todo se vendía. Estos comerciantes, usureros por añadidura, llegaron a las ciudades más ricas y a los centros en expansión y se enriquecieron rápidamente.

22 El portugués Diego de Vega, por ejemplo, pasó al Brasil en edad temprana y se estableció allí, donde, antes de dirigirse al Río de la Plata, dio cuerpo a importantes empresas. Molina, "Una historia desconocida". Como hombre de "grandes vistas financieras", al enterarse de las expediciones iniciadas por el obispo del Tucumán Francisco de Victoria, se dirigió hacia el Río de la Plata, adonde llegó en 1590. Arribó a nuestras costas en un navío de su propiedad y acompañado de amigos portugueses, también potentados de la región. Entre ellos se encontraban Antonio de Sosa y Antonio Fernández Barrios.

${ }^{23}$ Antonio Fernández Barrios llegó en los primeros navíos, probablemente en 1590, en compañía de Diego de Vega. Se desempeñó como alguacil mayor de la Hacienda Real, de 1602 a 1607. Su condición de portugués no le impidió ser elegido en los oficios de la ciudad, ya que ocupó el puesto de regidor en 1604 y de alcalde de la hermandad en 1606. Por otro lado, su condición de vecino consolidado le permitió abonar las fianzas de algunos vecinos, como la de Bernardo de León, depositario de la ciudad. Acuerdos del extinguido Cabildo de Buenos Aires, t. 2 (Buenos Aires: Archivo General de la Nación, 1895). 
quienes jugarían un destacado rol en la sociedad porteña de principios del siglo XVII. Estos mercaderes portugueses y españoles, llegados principalmente por la plata potosina y su intercambio por esclavos y otras mercaderías, no eran los mismos conquistadores o hijos de conquistadores de la fundación de la ciudad que llevaban a cabo los intercambios iniciales con Brasil y Paraguay. Ahora se trataba de un nuevo grupo de personas recientemente llegadas al puerto, portugueses y españoles, que se establecieron en la ciudad y comenzaron a organizar y controlar el comercio de ultramar a gran escala ${ }^{25}$. Poseedores de grandes capitales, contactos e influencias, manejaban los segmentos más importantes de las principales rutas comerciales. Tenían la capacidad, la experiencia, el crédito y los contactos necesarios para desempeñarse también como financistas, prestando dinero efectivo $\mathrm{u}$ otorgando créditos. Muchos de ellos eran considerados asimismo de origen innoble, por su condición de extranjeros o nuevos cristianos. Si bien la expresión "nuevo cristiano" no era sinónimo de comerciante, ellos constituyeron una mayoría importante de la asociación. Esta mancha en el honor de un individuo solo podía borrarla la riqueza ${ }^{26}$.

Estos no fueron los únicos que se vieron cautivados por el comercio que comenzó a desarrollarse por Buenos Aires, sino que también atrajo a poderosos funcionarios del Estado, que de él obtenían un complemento para los salarios de los cargos oficiales que recibían. Los miembros de este grupo estaban estrechamente ligados al sector dirigente que estuvo al frente de la ciudad hasta mediados del siglo XVII. Así, luego de mencionar a los primeros pobladores de la ciudad y de dar cuenta del arribo del grupo de los comerciantes, podemos decir que estamos frente a la estructuración de dos grupos diferentes: por un lado, el de los primeros pobladores, los Beneméritos, y, por otro, el de los "recién llegados", los Confederados.

\section{Mecanismos de conformación de la élite}

Los orígenes de lo que podríamos llamar la élite rioplatense debemos situarlos en los descendientes de los conquistadores, personajes prominentes, renombrados por su prestigio. Como consecuencia, desempeñaban un papel fundamental en la vida

\footnotetext{
${ }^{24}$ El alguacil de mar, el portugués Antonio de Sosa, llegado en 1590 en compañía de Diego de Vega y Antonio Fernández Barrios, fue designado como alguacil de la Real Hacienda por el tesorero Simón de Valdez.

${ }^{25}$ Gelman, "Economía natural".

${ }^{26}$ Entre los portugueses que vinieron al puerto, además de los grandes comerciantes, se encontraban también mercaderes de menor rango, tenderos y vendedores ambulantes que recorrían las poblaciones ofreciendo los artículos y contribuían así a la conformación de las redes comerciales, que se extendían también a través del Atlántico. Armas, Liberales, protestantes y masones.
} 
política y socioeconómica de la ciudad, controlando la mayor parte de los recursos productivos en las regiones donde estaban localizadas sus propiedades. Los méritos de los miembros de este grupo, como vimos, les dieron especiales recompensas por parte de la Corona: tierras y encomiendas. Era el grupo de los primeros vecinos conquistadores-encomenderos-terratenientes que iniciaron los contactos comerciales con Paraguay y Brasil.

Pero la pobreza de las encomiendas locales impedía aprovechar las extensas propiedades de tierra de que gozaban. Poseedores de poco capital, los Beneméritos llevaron una existencia dura en los primeros años $\mathrm{y}$, a menudo, solo tenían recursos suficienes para trabajar una parte de la concesión original. Por lo tanto, apremiados por la falta de capitales y para obtener dinero, se vieron obligados a alquilar sus indios a los recién llegados. Cuando no fue suficiente con el alquiler de los mismos, comenzaron a solicitar préstamos o créditos a quienes poseían el capital, de manera que terminaron por endeudarse. Finalmente, se vieron obligados en algunos casos a vender sus tierras y propiedades.

Este grupo de conquistadores y descendientes de conquistadores se encontraban en decadencia económica, sin dinero $\mathrm{y}$, la mayoría de ellos, endeudados con los comerciantes recientemente llegados a la ciudad. Por supuesto, no todos sufrieron el mismo destino y aquellos que mejor resistieron la situación se unieron al grupo Confederado, ya sea como socios o casando a sus hijas.

El historiador Jorge Gelman ${ }^{27}$ señala que de 1580 a 1640-1650 nos encontramos con dos períodos bien diferenciados en relación con las élites locales: en el primero, la ciudad habría estado dominada por el grupo Benemérito, y abarcaría aproximadamente de 1610 a 1620; en el segundo, a partir de esta fecha, la ciudad habría comenzado a estar bajo el dominio de los Confederados, que comenzaron a desplazar a los primeros controlando la actividad comercial que se desarrollaba por el puerto.

A diferencia de Gelman, quien ve en estos dos períodos una alternancia de las distintas élites en el poder, considero que lo que él discrimina en dos etapas estaría formando parte de un mismo proceso, justamente el de constitución del grupo dirigente de Buenos Aires. De manera que, hasta 1620 aproximadamente, la élite local se hallaba aún en proceso de formación. Hasta ese momento eran grupos de poder opuestos, pero no consituían per se una élite, en términos del sector que concentraba en sus manos tanto el poder y el honor como las riquezas.

Este proceso de configuración de la élite se inició con la llegada de los fundadores de Buenos Aires: ellos conformaron el primer Cabildo de la ciudad y constituyeron

${ }^{27}$ Gelman, "Cabildo y élite local”. 
el cuerpo elegible para desempeñarse en el mismo como regidores y alcaldes. Este grupo contaba con grandes honores y poder pero, como vimos, sus riquezas eran escasas. Cuando los comerciantes se establecieron en la ciudad, por su condición de comerciantes y extranjeros se les negó el derecho a ejercer cargos en el Cabildo, institución que regulaba las cuestiones del comercio local -además, siendo miembro del mismo, se contaba con más posibilidades de obtener mercedes de tierras $-{ }^{28}$. Eran comerciantes y extranjeros, carentes de honor y poder, por el momento, pero controlaban las riendas del comercio a larga distancia, lo cual les otorgaba inmensas riquezas. Esta gran disponibilidad de dinero les permitió comenzar a comprar las tierras y propiedades que los Beneméritos se veían en la obligación de vender para poder obtener dinero o para enfrentar las deudas que habían contraído. Entonces, ¿cómo logró constituirse la élite rioplatense del temprano siglo XVII?

Una de las principales estrategias que utilizaron los Confederados para perfilarse como el sector dirigente fue la organización y el monopolio del comercio a gran escala. En 1588, la Audiencia de Charcas informó al rey que el comercio que se estaba realizando a través del puerto de Buenos Aires permitía el ingreso al Perú de esclavos y otras mercaderías, las cuales eran cambiadas por plata que salía sin permiso real ${ }^{29}$. El rey prohibió entonces la entrada de esclavos y mercaderías procedentes del Brasil, a través de una Real Cédula de 1594, la cual fue reiterada al año siguiente. Solo quedaba autorizado el intercambio directo con España utilizando embarcaciones sevillanas, que debían contar con una licencia especial para ello. A pesar de la veda, el gobernador de la Provincia del Paraguay ${ }^{30}$, Fernando de Zárate (1593-1595) encontró una alternativa: pese al decretado cierre del puerto, se podría admitir el ingreso de barcos negreros en caso de arribadas forzosas -los cuales fingirían haber perdido el rumbo en su viaje-, si se paraba por causas climáticas o se requería el arreglo de desperfectos en la embarcación. Bastaba con admitir de esta forma la llegada del buque al puerto, apoderarse del

\footnotetext{
${ }^{28}$ Ibídem.

29 Resulta reveladora una carta del fiscal de la Audiencia, el licenciado Ruano Téllez, fechada el 1 de marzo de 1588, donde hacía llegar al monarca su parecer: "En las provincias del Paraguay y Río de la Plata, se ha descubierto una nueva navegación del Brasil. Si este puerto no se cierra se ha de henchir el Perú por allí de portugueses y otros extranjeros (...) por que cada día vienen más navíos de portugueses con negros y mercaderías y vendrán de Flandes, Francia e Inglaterra, donde a la continua llegan urcas de la Bahía de Todos los Santos y otros puertos del Brasil, y de ahí se derrotan a este puerto, adonde el inglés que pasó el estrecho de Magallanes, el año pasado de ochenta y siete tomó dos navíos el obispo del Tucumán, cargados de negros y mercaderías, que traía para vender aquí en el Perú". Molina, "Una historia desconocida".

${ }^{30}$ Buenos Aires formó parte de la vasta Provincia del Paraguay y Río de la Plata hasta 1617, cuando fue dividida en la Gobernación del Río de la Plata y la Gobernación del Paraguay.
} 
cargamento, liquidarlo en subasta pública y comprarlo personalmente o por medio de un testaferro. A esta táctica al margen de la ley, que a partir de entonces se haría habitual, se la denominó "contrabando ejemplar" "31.

En 1602, con el surgimiento de la Real Cédula de Permiso, se concedió por seis años a los vecinos de Buenos Aires el privilegio de enviar para Brasil -en navíos de su propiedad- una cantidad preestablecida de productos autóctonos. Como contrapartida, podían traer los productos necesarios para la vida diaria, pero estos no podrían llevarse fuera de los límites del municipio. Esta permisión prohibía terminantemente la importación de esclavos y la exportación de plata ${ }^{32}$.

Al año siguiente, Pedro Luis de Cabrera, teniente de gobernador de Hernandarias, aprovechando que este se encontraba en Asunción, comenzó a vender públicamente a los portugueses las permisiones de comercio que habían sido otorgadas por la Corona a los vecinos del puerto. Los lusitanos, además de comprarlas, no se limitaron a intercambiar los productos permitidos por la disposición ni a respetar la cantidad establecida ni a venderlos dentro de los límites del municipio. Como consecuencia, negros y géneros holandeses que entraban al puerto fueron destinados finalmente a Potosí, y de esa forma comenzaron a llegar al alto Perú una gran cantidad de esclavos procedentes del Río de la Plata.

Debido a que no se podía poner un límite a la entrada ilegal de negros por el puerto de Buenos Aires, arribaron a la ciudad, en 1606 y 1609, el tesorero real Simón de Valdez $^{33}$ y el contador Tomás Ferrufino, respectivamente. Poco tiempo después, a finales de ese mismo año, arribó a costas rioplatenses, solicitando arribada forzosa por pérdida de rumbo, un navío portugués llamado Nossa Senhora do Rosario que traía un cargamento de esclavos. El alguacil de mar, el portugués Antonio de Sosa, visitó entonces a Juan de Vergara ${ }^{34}$-quien había sido enviado como escribano de su majestad junto con Juan Pedrero de Trejo, juez de comisión de la Real Audiencia de La Plata, en 1602- para investigar los problemas de contrabando que

\footnotetext{
${ }^{31}$ R. Molina, Hernandarias (Buenos Aires: Lancestremere, 1948).

${ }^{32}$ Molina, "Una historia desconocida".

${ }^{33}$ Simón Valdez fue propuesto como tesorero real para Buenos Aires por el Consejo de Indias en 1605. Previamente, se había desempeñado como procurador de la ciudad de La Habana y como teniente capitán general en su Canarias natal. Fue, además, teneiente general de Buenos Aires por un año (1607), nombrado por Hermandaria. R. A. Molina, Diccionario biográfico de Buenos Aires. 1580-1720 (Buenos Aires: Academis Nacional de Historia, 2000).

${ }^{34}$ Vergara era natural de Sevilla, pero había pasado a Indias a temprana edad, haciendo escala en La Habana, Portobelo, Lima, Potosí y Tucumán antes de establecerse en Buenos Aires.
} 
se estaban dando en el puerto ${ }^{35}$. Fue designado por Hernandarias como su teniente de gobernador debido a su gran desempeño, pero Juan de Vergara finalmente trabó amistad con Simón de Valdez, Mateo Leal de Ayala y Diego de Vega, líderes y miembros principales del futuro grupo de los Confederados. Al momento del arribo del buque Nossa Senhora do Rosario, Vergara se desempeñaba como teniente de gobernador de Hernandarias, y el alguacil Sosa le propuso el siguiente trato: Vergara debería denunciar la carga ilegal del navío, la cual, de acuerdo con las leyes vigentes, debía venderse en subasta pública y darse la tercera parte de la misma al denunciante. En este caso, esa tercera parte la repartiría con el alguacil de mar Antonio de Sosa, que por su empleo estaba inhabilitado para retener porcentaje alguno. Vergara aceptó la propuesta. Solo restaba que Simón de Valdez, como tesorero real, realizara la subasta; como resultado, el único que hizo ofertas fue el portugués Diego de Vega, a quien se adjudicó el lote. Finalmente, los esclavos fueron remitidos legalmente a Potosí para su venta. Una vez involucrados en esta empresa ilícita, Juan de Vergara y Simón de Valdez se asociaron con Diego de Vega. Comenzaron entonces a organizar el arribo de más navíos negreros en supuesta arribada forzosa.

La organización y el control del comercio ilegal a gran escala que se desarrollaba en el puerto fue la principal estrategia que llevaron a cabo los miembros del grupo Confederado para convertirse en la élite local. Este control otorgaba, además, grandes riquezas, que les posibilitaron llevar adelante la compra de inmuebles y hacerse de esa forma con la mayor parte de las propiedades de los antiguos Beneméritos. Al contar con una gran reserva de dinero, comenzaron a prestarlo y a otorgar créditos, creando así una gran red de complicidades, dependencias y subordinaciones. En 1606, el portugués Antonio de Sosa, que había llegado a la ciudad en 1590, comenzó a adquirir tierras y bienes de ciertos Beneméritos endeudados $^{36}$. De la misma forma, Juan de Vergara, miembro vital de los Confederados, fue el principal exponente de la compra de inmuebles a los Beneméritos: compró a Hernandarias una chacra en el Río de las Conchas y otra a Julián Pabón, de los primeros fundadores y pobladores del puerto que recibió tierras de Garay y que también ocupó destacados puestos públicos en la ciudad en la década de $1610^{37}$; y también negoció inmuebles con Bartolomé López, de los primeros vecinos de la ciudad, y con la viuda del capitán Víctor Casco de Mendoza

\footnotetext{
${ }^{35}$ Carta de Juan de Vergara a S. M., fechada en el Campo, a 20 leguas de Buenos Aires, a 8 de septiembre de 1630. E. Peña, Don Francisco de Céspedes. Noticias sobre su gobierno en el Río de la Plata. 1624-1632 (Buenos Aires: Coni, 1916).

${ }^{36}$ R. A. Molina, "Biografía cronológica de los primeros oficiales y funcionarios de la Hacienda Real en los 50 años siguientes a la fundación de Buenos Aires". Historia (Buenos Aires), Año 10, núm 38 (1965): 67-93.

${ }^{37}$ Acuerdos del Extinguido Cabildo de Buenos Aires.
} 
-Benemérito que se pasaría al bando de los Confederados-, entre otros ${ }^{38}$. El ex gobernador de Buenos Aires, Francés Beaumont y Navarra, quien se aliaría con el grupo de los comerciantes, compró una chacra de Juan Ortiz de Zárate, uno de los primeros pobladores del Río de la Plata ${ }^{39}$. Por su parte, Diego de Vega realizó la compra de una estancia a Julián Pabón y otra a Felipe Nabarro ${ }^{40}$, entre otras ${ }^{41}$. Asimismo, los Confederados no solo realizaron la compra de inmuebles pertenecientes a vecinos Beneméritos para socavar su influencia, sino que llevaron a cabo distintas represalias contra todos aquellos que se interpusieron en sus objetivos, llegando incluso a terminar con sus vidas.

Paralelamente a estas tácticas de control y monopolio del comercio ilegal y compra de bienes, los Confederados habían empezado a vincularse en matrimonio con las hijas de los antiguos terratenientes-encomenderos. De esta forma, al convertirse en miembros de las primeras casas de Buenos Aires, contaban con un plus derivado del honor de la familia de la novia, descendiente de los conquistadores. De la misma manera, debido a que los miembros de la familia constituían una importante reserva de influencias y recursos, y a que el parentesco político era tan fuerte y vinculante como el consanguíneo, los Confederados planificaron los matrimonios con las hijas de los antiguos hacendados, considerándolos movimientos estratégicos que consolidarían y ampliarían su gama de contactos, además de otorgar beneficios económicos a los endeudados Beneméritos. Podemos señalar entre estas uniones las de los capitanes Francisco Pérez de Burgos y Alonso Guerrero de Ayala, ambos Beneméritos, con las hijas de Mateo Leal de Ayala. También el matrimonio de Leonor de Aguilar y Burgos, hija del Francisco Pérez de Burgos $^{42}$, con Francisco de Manzanares, Benemérito que se aliaría a los Confederados a partir de $1614^{43}$.

La gran disponibilidad de dinero de los Confederados proveniente del monopolio del comercio ilícito, además de posibilitarles la compra de inmuebles, les permitió prestar dinero y crear así una gran red de complicidades y dependencias. De esta manera ya habían logrado conquistar el poder económico y poseer cierto prestigio e influencias, debido a los medios por los que actuaban; ahora les faltaba

\footnotetext{
38 Testamento de Juan de Vergara. R. A. Molina, "Juan de Vergara, señor de vidas y haciendas en el Buenos Aires del siglo XVII", Boletín de la Academia Nacional de Historia (Buenos Aires) vol 24- 25 (1950-1951):51-143.

${ }^{39}$ Molina, Diccionario biográfico.

${ }^{40}$ También Navarro o Naharro.

${ }^{41}$ Molina, "Una historia desconocida".

${ }^{42}$ Francisco Pérez de Burgos era español peninsular y pasó a Indias en 1581 ejerciendo el cargo de escribano real hasta 1606.

${ }^{43}$ E. Saguier "Political impact of immigration and commercial penetration on intracolonial struggles: Buenos Aires in the early seventeenth century", Jahrbuch für Geschichte. Lateinamerikas 22 (1985):43-166.
} 
conquistar y consolidarse en el poder político. Esta conquista comenzó en 1614; gracias a las subordinaciones que establecieron y al temor que generaban, lograron obtener el control del Cabildo antes de recurrir a la compra de cargos. Los Confederados utilizaron la presión, la influencia e incluso el soborno a los miembros salientes del Cabildo, que ahora debían elegir a los nuevos cabildantes, para lograr una elección que los favoreciera. De esta manera, en las elecciones de 1614, el grupo de los Confederados logró que los cabildantes salientes votaran por uno de los suyos o por un Benemérito que estuviese en connivencia con ellos ${ }^{44}$.

Hacia 1613, el Cabildo parecía constituir el último espacio donde los Beneméritos podían ejercer cierto poder. Lo conformaban todos miembros Beneméritos, los alcaldes de primer y segundo voto Francisco de Salas y Francisco Manzanares; los seis regidores: Domingo Gribeo, Felipe Nabarro, Gonzalo Carvajal, Miguel del Corro, Bartolomé Frutos y Juan Quinteros ${ }^{45}$. En las elecciones para el Cabildo entrante del año $1614^{46}$ se cometieron algunas irregularidades: el día anterior fueron apresados el escribano del Cabildo Cristóbal Remón y el regidor Domingo Gribeo, como parte de una treta organizada por los Confederados para ganar la elección del cuerpo. Cabe señalar, además, que en ese momento el regidor Juan Quinteros se encontraba en prisión ${ }^{47}$ y que, a cambio de un voto favorable a los Confederados, fue puesto en libertad por el Justicia Mayor, Mateo Leal de Ayala, también Confederado.

El resultado de la elección fue el siguiente: Juan de Vergara y Sebastián de Orduña, ambos Confederados, salieron alcaldes ordinarios, y este último también, alférez real. Los capitanes fueron Víctor Casco de Mendoza, Francisco Romero, Francisco Muñoz, y regidores, Francisco Pérez de Burgos, Hernán Suárez, y Bartolomé López; Diego de Trigueros y el capitán Felipe Nabarro quedaron de alcaldes de la Santa Hermandad. Víctor Casco de Mendoza, Francisco Muñoz, Bartolomé López,

\footnotetext{
${ }^{44}$ Para Eduardo Saguier las estrategias utilizadas por los Confederados destinadas a romper el "bloque Benemérito" se fundamentaron en la compra de cargos del Cabildo, en la subordinación de los oficiales de la burocracia y en la "conquista de la sociedad civil". En "Political impact of immigration", 151. Para este autor, los Confederados comenzaron a dominar el Cabildo a partir de la compra de oficios. Por otro lado, para Jorge Gelman, el control del Cabildo fue fundamental en la consolidación de los Confederados. "Cabildo y élite local".

${ }^{45}$ Acuerdos del Extinguido Cabildo, 3: libs. II y III, 1.

${ }^{46}$ En el Nuevo Mundo, las leyes establecían que los cargos en el Cabildo fuesen anuales y que la elección de las nuevas autoridades debía efectuarse cada 1 de enero, cuando el Cabildo saliente elegiría al entrante. El de Buenos Aires estaba conformado por dos alcaldes y seis regidores con voto. También solían votar los oficiales reales, que en este período eran el tesorero Simón de Valdez, el contador Tomás Ferrufino y el depositario Bernardo de León.

${ }^{47}$ Acuerdos del Extinguido Cabildo, 3: lib. II, 2.
} 
y el capitán Felipe Nabarro, antiguos Beneméritos, a partir de entonces, y seducidos por los Confederados, se les sumaron. De esta manera, el grupo consiguió asegurarse la mayoría en el cuerpo ${ }^{48}$.

Coincido con la conclusión a la que arriba Jorge Gelman, según la cual, sin lugar a dudas, fue en 1617, através de la compra de cargos del Cabildo, que los Confederados consolidaron su poder, pero, para que esto pudiese llevarse a cabo, antes fue necesario que se produjera el acaparamiento de cargos del Cabildo a través del ejercicio de influencias y compra de votos, como sucedió en la elección de 1614. Tres años después, Juan de Vergara -principal líder Confederado-, que a al sazón se encontraba en Potosí, compró seis regimientos que distribuyó entre distintos parientes y conocidos. Los repartió entre su suegro Diego de Trigueros, sus dos concuñados, Juan Barragán y Tomás Rosendo, su amigo y socio, el portugués Francisco de Melo, y su ahijado Juan Bautista Ángel. El sexto se lo reservó para su servicio ${ }^{49}$.

Este proceso de construcción y configuración de la élite, que dio paso al dominio y control total por parte del grupo Confederado (comerciantes-terratenientes), coincidió con la desarticulación de los antiguos hacendados del bando de los Beneméritos, quienes, a través de las distintas estrategias anteriormente vistas, fueron cautivados por el grupo de los comerciantes y pasaron a formar parte del mismo y a involucrarse en sus actividades ilícitas. De esta forma, como bien señala Gelman $^{50}$, esta división en facciones se disipó hacia 1610. En este momento comenzó a producise la absorción de los Beneméritos por los Confederados, que en adelante se convirtieron en el grupo dirigente rioplatense, con control tanto del poder y el honor como de la riqueza de la sociedad portuaria.

Por lo tanto, el proceso de conformación de la élite rioplatense de principios del siglo XVII (que venía realizándose desde que los comerciantes Confederados

\footnotetext{
48 Ibídem, 10.

${ }^{49}$ La venta de oficios y cargos desempeñó un papel fundamental en la consolidación de los Confederados como grupo dirigente de Buenos Aires. La venta de oficios sin jurisdicción comenzó a aplicarse en el reinado de Felipe II y se aceleró a partir de 1581. Esta política se basaba en la idea según la cual los oficios formaban parte del cuerpo de la monarquía e instaurarlos era una de las regalías del soberano. Aquellos cargos que no intervenían en la administración de justicia (escribanos, regidores, alguaciles y otros) pasaron a ser oficios vendibles y renunciables, es decir, transferibles a un tercero. Las ventas se efectuaban por remate público, generalmente en Potosí. En nuestro ámbito, la aplicación del sistema está registrada desde principios del siglo XVII, pero fue en las cercanías de la segunda década donde comenzó a darse con mayor asiduidad. Z. Moutoukías, Contrabando y control. Gelman hace especial hincapié en el control del Cabildo para la conformación del poder de los Confederados. Gelman, "Cabildo y élite local".

${ }^{50}$ Ibídem.
} 
organizaron el comercio a gran escala) derivó en el dominio y control de los recursos económicos y políticos por parte del nuevo grupo, compuesto en su mayoría por miembros pertenecientes al grupo Confederado (comerciantesterratenientes) y coincidió con la desarticulación de los antiguos hacendadosencomenderos del bando de los Beneméritos. Queda ilustrado así que la nueva élite no estuvo compuesta únicamente por comerciantes españoles o portugueses, los integrantes originarios del grupo Confederado, sino que se sumaron a ellos muchos Beneméritos, que fueron cautivados por el dinero y poder que estos ejercían y que, abandonando sus antiguos valores.

Finalmente, entonces, no se produjo una alternancia en el poder entre la élite benemérita y la de los antiguos Confederados. Al contrario, emergió un nuevo sector, síntesis de quienes formaron fila tanto en el bando de los antiguos Confederados como en el de los Beneméritos. De esta manera, el nuevo grupo de élite se encontró al frente de la sociedad desde la segunda década hasta mediados del siglo XVII. A partir de entonces, con la concentración de riquezas, poder y prestigio en sus manos, se produjo el surgimiento de un nuevo grupo, mixto, que se encontraría al frente de la sociedad porteña y tendría un control total sobre los dominios económico, político y social de la ciudad.

Fue de esta forma, en consecuencia, como se llevó a cabo el surgimiento de una élite en el Río de la Plata, nueva en términos de su composición -más variada, debido al origen y profesión de sus integrantes-, nueva en términos de ideología resultado también de las distintas ocupaciones, oficios, valores y procedencia de sus integrantes-, y distinta en su comportamiento -debido a sus intereses, a la orientación de sus negocios, tanto hacia el mercado interno como externo, y a las conductas que asumían-. Fue una élite mixta por la nueva conciencia que adquirieron, resultado de la variedad de orígenes y oficios, que, a su vez, enriqueció las experiencias y condicionó los comportamientos del nuevo grupo. $\mathrm{Su}$ aparición da cuenta de los variados caracteres, ánimos e intereses de los sujetos coloniales.

\section{Bibliografía}

\section{Fuentes primarias}

Acuerdos del extinguido Cabildo de Buenos Aires. 3. t. Buenos Aires: Archivo General de la Nación, 1895.

\section{Fuentes secundarias}


Altman, I. "A new world in the old: local society and spanish emigration to the Indies". En To make America. European emigration in the early modern period. Comp. Altman y Honr, 30-58. California: University of California Press, 1991.

Armas Asin, F. Liberales, protestantes y masones. Modernidad y tolerancia religiosa en el Perú del siglo XIX. Lima: Pontificia Universidad Católica del Perú y Centro de Estudios Regionales Andinos "Bartólome de Las Casas", 1998.

Assadourian, C. S. Tráfico de esclavos en Córdoba. De Angola a Potosí. Siglos XVI-XVII. Córdoba: Universidad Nacional de Córdoba. 1966.

. "Integración y desintegración regional en el espacio colonial. Un enfoque histórico". En El sistema de la economía colonial. Lima: Instituto de Estudios Peruanos, 1982.

Canabrava, A. P. O comercio portugués no Río da Prata. 1580-1644. Sao Paulo: Universidad de Sao Paulo, 1944.

Colson, E. "Antropología política en las relaciones de poder". En Antropología politica. Comp. Llobera. Barcelona: Anagrama. 1985.

Domínguez Ortiz, A. El Antiguo Régimen: Los Reyes Católicos y los Austrias. Historia de España. Dir. Miguel Artola. Madrid: Alianza Editorial. 1981.

Elliot, J. H. "Europa y América en los siglos XVI y XVII". En Historia de América Latina. Comp. Leslie Bethell. T. 2. América Latina colonial: Europa y América en los siglos XVI, XVII y XVIII. Barcelona: Crítica, 1990.

Foucault, M. Un diálogo sobre el poder. Madrid: Alianza, 1981.

. Microfisica del poder. Madrid: Alianza, 1986.

. Las redes del poder. Buenos Aires: Almagesto 1993.

Gelman, J. "Cabildo y élite local: Buenos Aires en el siglo XVII". Revista Latinoamericana de Historia Económica y Social (Lima), 6 (1985):3-27.

. "Economía natural-Economía monetaria. Los grupos dirigentes de Buenos Aires a principios del siglo XVII". Anuario de Estudios Americanos (Sevilla), XLIV (1987): 89-107. 
Haring, C. H. El imperio español en América. México: Alianza Editorial, 1990.

Levene, R. Investigaciones acerca de la historia económica del virreinato del Plata. 2 vols. La Plata: Academia Nacional de la Historia, 1927-28.

Levillier, R. Correspondencia de la Ciudad de Buenos Aires con los Reyes de España. 2 vols. Buenos Aires: Municipalidad de Buenos Aires, 1915.

Lopez, Beltrán C. Alianzas familiares. Élite, género y negocios en La Paz, S. XVII. Lima: Instituto de Estudios Peruanos (IEP), 1998.

Maeder, E. Nómina de gobernantes civiles y eclesiásticos de la Argentina durante la época española (1500-1810). Buenos Aires: UNNE; Instituto de Historia Facultad de Humanidades. 1973.

Maravall, J. A. Estudios de historia del pensamiento español. Madrid: Ediciones Cultura Hispánica, 1973.

Molina, R. Hernandarias. Buenos Aires: Lancestremere, 1948.

"Juan de Vergara, señor de vidas y haciendas en el Buenos Aires del siglo XVII". Boletín de la Academia Nacional de Historia (Buenos Aires), vol. 24-25 (1950-1951):51-143.

. “¿Quiénes fueron los verdaderos fundadores de Buenos Aires? Una lista desconocida”. Historia (Buenos Aires), núm. 1 (1955): 21-55.

"Una historia desconocida sobre los navíos de registro arribados a Buenos Aires en el siglo XVII". Revista Historia (Buenos Aires) 23 (1959):5-67.

. "Biografía cronológica de los primeros oficiales y funcionarios de la Hacienda Real en los 50 años siguientes a la fundación de Buenos Aires". Historia (Buenos Aires), Año 10, núm 38 (1965):67-93.

Las primeras experiencias comerciales del Plata: el comercio marítimo, 1580-1700. Buenos Aires: Talleres Gráficos Borrego, 1966.

Moutoukias, Z. Contrabando y control colonial en el siglo XVII. Buenos Aires: Centro Editor de América Latina, 1988.

"Power, corruption and commerce: The making of the local administrative structure in seventeenth century". Hispanic American Historical Review (Durham, Estados Unidos), 68, núm. 4 (1988): 771-801. 
"Redes, autoridad y negocios: racionalidad empresaria y consenso colonial en Buenos Aires (segunda mitad del siglo XVIII)". Annales (Buenos Aires), 47 núm. 4-5 (julio-octubre 1992):3-23.

Pastells, P. Historia de la Compañia de Jesús en la provincia del Paraguay (Argentina, Paraguay, Uruguay, Perú, Bolivia y Brasil). Sevilla: Archivo General de Indias, 1912-1949.

Peña, E. Don Francisco de Céspedes. Noticias sobre su gobierno en el Río de la Plata. 1624-1632. Buenos Aires: Editorial Coni, 1916.

Quarleri, L. "Élite local, burocracia y reformas borbónicas: La administración de temporalidades de La Rioja". Revista Población y Sociedad (Tucumán, Argentina), núms. 8 y 9 (2001-2002): 177-210.

Romero, J. L. Latinoamérica: las ciudades y las ideas. Buenos Aires: Siglo XXI, 1986.

Saguier E. "Political impact of immigration and commercial penetration on intracolonial struggles: Buenos Aires in the early seventeenth century". Jahrbuch für Geschichte Lateinamerikas 22 (1985):43-166.

- "La corrupción administrativa como mecanismo de acumulación y engendrador de una burguesía comercial local". Anuario de Estudios Americanos, separata del tomo XLVI (Sevilla), (1989): 269-303.

Stern, S. "Paradigmas de la conquista: historiografía y política". Boletín del Instituto de Historia Argentina y Americana Dr. E. Ravignani. 3a serie (Buenos Aires), núm. 6 (1992): 94-109.

Torre Revello, J. La sociedad colonial. Buenos Aires entre los siglos XVI y XIX. Buenos Aires: Ediciones Pannediele, 1970.

- Documentos históricos y geográficos relativos a la conquista y colonización rioplatense. Vol. 1. Buenos Aires: Comisión Oficial del IV Centenario de la primera fundación de Buenos Aires, 1977.

Fecha de recepción: 28 de abril de 2005.

Fecha de aceptación: 23 de agosto de 2005. 